\title{
Teología de la liberación, 40 años después Balance y perspectivas
}

\author{
Víctor Codina, S.J., \\ Profesor emérito de la Universidad Católica, \\ Boliviana de Cochabamba
}

No es fácil escribir sobre la teología de la liberación (TDL), su evolución y su horizonte futuro, en parte porque nos falta todavía perspectiva histórica suficiente para poder observar serenamente y desde más lejos su proceso, y en parte porque sobre este tema ya hay abundante literatura.

Sin querer hacer alarde bibliográfico, quiero citar Mysterium liberationis como presentación muy completa de lo que ha sido la TDL desde sus inicios ${ }^{1}$ y el libro dirigido por L. C. Susin, Y el mar se abrió, donde se hace un balance de los 30 últimos años de la teología latinoamericana ${ }^{2}$. También algunas revistas han dedicado números extraordinarios con motivo de los 40 años de la TDL ${ }^{3}$.

Por todo ello, para no repetir lo ya conocido y para darle a este escrito un carácter más vivencial y narrativo, me ceñiré a presentar mi experiencia de haber

1. I. Ellacuría y J. Sobrino (eds.), Mysterium liberationis. Conceptos fundamentales de la teología de la liberación, vols. I-II, Trotta, Madrid, 1990. El título Mysterium liberationis es una réplica latinoamericana al Mysterium salutis, publicado por los teólogos europeos después del Vaticano II. Cuando fue publicado Mysterium liberationis en 1990, ya hacía un año que I. Ellacuría había sido asesinado. De esta obra es especialmente interesante para nuestro tema el capítulo de R. Oliveros, "Historia de la teología de la liberación", vol. I, op. cit., pp. 17-30.

2. L. C. Susin Latina, Y el mar se abrió. Treinta años de teología en América Latina, Sal Terrae, Santander, 2001.

3. Por ejemplo, "La teología de la liberación, cuarenta años después: retos y desafíos", Alternativas, año 19, n. ${ }^{\text { }} 44$, julio-diciembre 2012; "Reflexiones. 40 años de la teología de la liberación: balances y perspectivas", Vinculum, año 60 , n. . 250, eneromarzo 2013, donde se recogen aportes de la Comisión Teológica Latinoamericana ASETT/EATWOT. 
participado en tres encuentros o congresos sobre TDL: El Escorial (Madrid) 1972, El Escorial (Madrid) 1992 y Unisinos (São Lepoldo) 2012.

Sin duda, ha habido otros congresos y encuentros importantes sobre TDL, por ejemplo los de México (1975), Detroit (1975), Dar-es Salam (1976) de la Asociación de Teólogos del Tercer Mundo, encuentros sobre TDL con motivo de las reuniones del Foro Social Mundial, encuentros de teólogas feministas, de teología india, etc. Pero me limito y concentro en los tres antes señalados no solo porque participé activamente en ellos, sino porque recubren suficientemente y de modo significativo el espacio recorrido en los 40 años de la TDL.

\section{Encuentro de El Escorial-Madrid 1972}

Aunque parezca extraño, en el encuentro de El Escorial (Madrid) 1972, por primera vez se reunieron en España gran parte de los teólogos de la liberación que vivían dispersos por la geografía latinoamericana. Y también, paradójicamente, este encuentro, auspiciado por el Instituto Fe y Secularidad de Madrid, que dirigía Alfonso Álvarez Bolado, se celebraba junto al Monasterio de San Lorenzo de El Escorial, edificado por el rey Felipe II, donde yacen enterrados los soberanos de la Casa de Austria que consolidaron la conquista y colonización de la América hispana. Añadamos que se celebró en plena dictadura franquista con intervenciones de la Policía española para investigar quiénes estábamos reunidos y sobre qué tema versaba la reunión. Posiblemente sospechaban que se trataba de algo "subversivo".

La fecha de este encuentro es sintomática tanto desde el punto de vista sociopolítico como del eclesial. Después de la Revolución cubana (1959), habían sucedido en América Latina profundos cambios sociales, por ejemplo, en Perú y Chile, mientras que en Brasil comenzaba la dictadura militar. La figura del Che Guevara, asesinado por los militares en Bolivia en 1967, se convertía en un mito para las generaciones jóvenes y muchos creían que el socialismo que había comenzado en Chile con Allende se iba a extender rápidamente por toda América Latina.

En el contexto eclesial, la Iglesia vivía la etapa postconciliar de Pablo VI, que en 1967 había publicado la encíclica Populorum progressio y en 1968 había convocado la reunión de Medellín. Medellín fue un evento realmente pentecostal para América Latina, ya que en esta conferencia, el Vaticano II fue recibido y asumido creativamente por el continente latinoamericano. Los obispos en Medellín escucharon el clamor del pueblo pobre y oprimido, discernieron en este grito un

4. Las ponencias de este encuentro fueron publicadas por el Instituto Fe y Secularidad bajo el significativo título Fe cristiana y cambio social en América Latina, Sígueme, Salamanca, 1973. Cf. V. Codina, Diario de un teólogo del posconcilio, Editorial San Pablo, Bogotá, 2013, pp. 26-27. 
signo de los tiempos y decidieron responder a este clamor y acompañar al pueblo en sus ansias de justicia y liberación de las estructuras de pecado, para pasar de condiciones de vida inhumanas a condiciones de vida más humanas y justas.

El paradigma del Éxodo, ausente en la reflexión eclesiológica del Vaticano II sobre el Pueblo de Dios ( $L G$ II), aflora claramente en Medellín. Parece que el sueño de Juan XXIII sobre una Iglesia de los pobres comienza a hacerse realidad en América Latina...

El Encuentro de El Escorial 1972 no es una reunión de cristianos por el socialismo, sino un congreso teológico donde los ponentes y directores de seminarios representan un espectro amplio de una familia de opciones diferenciadas, que van todas ellas más allá del desarrollismo y que serán el núcleo básico de lo que luego se llamará TDL. En 1971, Gustavo Gutiérrez publica en Perú su libro Teología de la liberación, pero ya en 1968 Rubén Alves, de la Iglesia evangélica, había publicado su tesis doctoral Toward a Theology of Liberation. La TDL nace ya ecuménica.

No es exagerado afirmar que el Encuentro de El Escorial 1972 fue, de hecho, si no un momento fundante de la TDL, sí un momento fundamental para su constitución como línea teológica.

En coherencia con la postura teológica latinoamericana de partir de la realidad y de discernir los signos de los tiempos, el Encuentro de El Escorial comienza por señalar los factores económicos y las fuerzas políticas presentes en el proceso de liberación (R. Ames), la historia de la fe cristiana y el cambio social en América Latina (E. Dussel) y las ideologías y movimientos sociales en América Latina (J. Comblin).

Este encuadramiento socio-eclesial permite señalar que América Latina no vive simplemente bajo el paradigma del subdesarrollo, sino de la dependencia y que debe luchar por la liberación, una de cuyas alternativas puede ser la opción socialista.

En este contexto y a la luz de la historia de la evangelización de América Latina, la TDL es un momento reflexivo profético que quiere reaccionar contra la ideología idolátrica del poder occidental que en la conquista contaminó la fe cristiana. Los movimientos sociales de América Latina son antiimperialistas y populares y no usan el marxismo como inspiración, sino como un instrumento de análisis social para superar la situación de dependencia-opresión.

Esta tarea liberadora es ecuménica y transconfesional (J. Míguez Bonino), y supera una visión de la fe cristiana meramente individualista y en cambio busca analizar los fenómenos de la supraestructura de cara a la lucha real por la liberación. Hay que reformular desde esta óptica, conceptos teológicos como Dios, pecado, salvación, etc. 
Pero fue sin duda la ponencia de Gustavo Gutiérrez sobre Evangelio y praxis liberadora la que suscitó mayor impacto y conmoción en El Escorial, pues mostró tanto la dimensión espiritual del encuentro con Cristo en el pobre como la exigencia de un quehacer teológico que no reduce la salvación a lo socioeconómico o sociopolítico, pero afirma que la salvación se da a través de las mediaciones históricas liberadoras. De ahí la relación profunda entre fe, teología y praxis liberadora. La teología es un acto segundo.

Personalmente, me llamó la atención la importancia que se dio en este Encuentro a la religión del pueblo, síntesis entre catolicismo y tradiciones ancestrales, que por su gran profundidad y extensión puede jugar un papel decisivo, positivo o negativo, en el proceso liberador. Las ponencias de A. Büntig, S. Galilea y la simpatía de J. C. Scannone por este tema resultaban novedosas y chocantes para el mundo secular europeo, muy crítico frente a la religiosidad popular que consideraba preconciliar y alienante.

Participé en un seminario sobre nuevas formas de vida religiosa y de comunidades religiosas en América Latina, dirigido por la Confederación Latinoamericana y Caribeña de Religiosos y Religiosas, CLAR (M. Edwards y María Agudelo), donde se insistió en la importancia de la opción por los pobres y de la presencia de pequeñas comunidades religiosas en ambientes y barrios populares, lo que luego se formulará como vida religiosa inserta.

Es difícil sintetizar lo que representó este primer encuentro de El Escorial, pero podemos subrayar algunos de los aportes que me parecieron más significativos:

- Estamos ante una ruptura epistemológica, un modo nuevo de hacer teología, una teología que no es mero reflejo de la teología europea como hasta ahora, sino que parte de la realidad histórica del pueblo pobre y oprimido de América Latina, que lucha por un cambio social y su liberación de estructuras injustas y dependientes 5 .

- Esta nueva teología no es parcial, ni de genitivo, no se reduce a una moral política o a la doctrina social de la Iglesia, sino que es una visión global de la fe cristiana desde otro lugar teológico, desde los pobres, y orientada a la praxis liberadora.

5. No me resisto a citar un testimonio elocuente sobre esta novedad de la teología del Sur que nos narra J. García Roca: "Recuerdo la confesión personal que me hizo el mayor teólogo español del siglo XX, el padre Alfaro. Allá por el año 1973, visitó Latinoamérica a conferenciar. A su regreso me reconoció que el día que la Iglesia mirara al Sur, ni la teología ni la moral ni la organización superarían la prueba. Reconozco que la teología que he hecho durante toda mi vida no servirá en el futuro". J. García Roca, "Otro horizonte para las relaciones de la Iglesia con el mundo", Éxodo, n. ${ }^{\circ} 118$, abril 2013, pp. 35-44, citas 42-43. 
- A diferencia del mundo desarrollado secular europeo y nordatlántico, esta teología parte de un pueblo a la vez profundamente religioso-cristiano y pobre.

- Esta teología, como toda auténtica reflexión teológica, nace de una profunda experiencia espiritual: el misterio de Cristo presente en el pobre, algo realmente evangélico, nazareno, pascual.

- El recurso socio-analítico de las ciencias sociales no es el motor de esta teología, sino un instrumento de mediación que se debe usar con discernimiento crítico y a la luz del Evangelio, sin sacralizarlo ni demonizarlo, como lo hicieron en su tiempo los Padres de la Iglesia con el platonismo y santo Tomás con el aristotelismo.

- Dentro de esta familia de opciones diferenciadas, aparecieron ya en El Escorial posturas más ideologizadas (H. Assmann) y posturas más evangélicas (G. Gutiérrez), tendencias más elitistas (J. L. Segundo) y más populares (S. Galilea, R. Poblete, J. C. Scannone), aproximaciones más sociológicas, históricas y políticas (R. Ames, J. L. Segundo, G. Arroyo, E. Dussel), y otras más eclesiales y pastorales (Mons. Cándido Padín, N. Zevallos, C. de Lora, M. Agudelo).

El tono general del Encuentro fue positivo, esperanzador, utópico, casi demasiado optimista. Hubo una intervención de J. I. González Faus que exhortó a no olvidarse de la cruz. Lo que sucedió en los años siguientes (dictaduras militares, persecución, martirio, conflictos con Roma...) dio la razón a la advertencia profética de González Faus.

Podemos resumir este Encuentro afirmando que se realizó bajo el paradigma del Éxodo: un pueblo esclavizado y oprimido que busca su liberación de la dependencia y de la esclavitud.

Digamos finalmente que los ponentes y disertantes de El Escorial 1972 corresponden a la primera generación de los iniciadores de la TDL. No formaban parte de los ponentes otras figuras teológicas que luego jugarán un papel muy significativo en la TDL, como I. Ellacuría, J. Sobrino, Leonardo y Clodovis Boff, J. B. Libanio, Frei Betto, C. Mesters, R. Muñoz, P. Richard, C. Bravo, P. Trigo, D. Irarrázaval...

Tampoco había presencia de mujeres entre los ponentes. También en este punto habrá luego notables cambios, pues cada vez más las mujeres participarán en la corriente teológica liberadora: Ivonne Gebara, María Clara L. de Bingemer, Elsa Támez, Ana María Tepidinho, Teresa Porcile, Carmelita Freitas, Georgina Zubiría, Alcira Ágreda, Maricarmen Bracamonte, Luzia Weiler, Sofía Chipana, Isabel Barroso, Antonieta Potente, Gisella Gómez, Adriana Curaqueo, Marcela Bonafede, María José Caram, Bárbara Brucker, Margot Bremen, Vilma Moreira, Vera Bonbonatto, Viginia Azcuy, Consuelo Vélez... 
Este primer Encuentro contrasta mucho con el segundo Encuentro de El Escorial en 1992, veinte años después.

\section{Encuentro de El Escorial 1992}

El contexto social y eclesial ha cambiado profundamente. América Latina ha vivido duros años de dictaduras militares, sobre todo en Centroamérica y el Cono Sur. La ideología de la doctrina de la seguridad nacional ha producido persecuciones, exilios, torturas y asesinatos, lo cual ha provocado como reacción movimientos de insurgencia guerrillera. Además de los conocidos martirios de Romero y Angelleli, de teólogos como Ellacuría y compañeros de la UCA, de religiosos y religiosas, hay verdaderas masacres de campesinos, líderes obreros, indígenas, catequistas, mujeres, agentes de pastoral, etc. Es el Viernes Santo de la pasión del pueblo.

El triunfo del sandinismo en Nicaragua (1979) y la lenta recuperación de débiles democracias en varias naciones generan un cierto alivio esperanzador. Pero la pobreza en estos años se ha incrementado, la brecha entre pobres y ricos ha crecido, lo mismo que ha aumentado la deuda externa, el narcotráfico y la violencia (Sendero Luminoso, guerrilla colombiana...).

A nivel mundial, la caída de Muro de Berlín (1989) ha cambiado el escenario geopolítico, el capitalismo neoliberal se proclama como la única salvación universal y el final de la historia (F. Fukuyama).

En cuanto a la Iglesia católica, el pontificado de Juan Pablo II inaugura una nueva etapa en la que el papa proyecta a toda la Iglesia su experiencia polaca, una experiencia premoderna en lo eclesial y postmarxista en lo social ${ }^{6}$. Se hizo famosa la imagen de Juan Pablo II reprimiendo en el aeropuerto de Managua al sacerdote poeta y ministro de Cultura sandinista Ernesto Cardenal, arrodillado a sus pies. Obando será el nuevo Wyszynski. Parece que con Juan Pablo II se inicia para toda la Iglesia una doctrina de la seguridad eclesial.

La TDL sufre una dura crítica de parte de la Congregación para la Doctrina de la Fe, que preside el cardenal Josef Ratzinger (1984, Libertatis nuntius). J. L. Segundo responde a Ratzinger y le acusa de atacar no solo a la TDL, sino al mismo Vaticano $\mathrm{II}^{7}$. Una segunda Instrucción (1986, Libertatis conscientia), mucho más matizada, rebaja el tono de la primera y reconoce que el concepto de liberación tiene fundamento cristiano ${ }^{8}$. Más tarde, en 1986, Juan Pablo II escribe

6. J. I. González Faus, Comprender a Karol Wojtyla, Sal Terrae, Santander, 2005.

7. J. L. Segundo, La teología de la liberación. Respuesta al cardenal Ratzinger, Madrid, 1985.

8. I. Ellacuría observa con ironía que, sin embargo, en el libro de Ratzinger, Introducción al cristianismo, no aparece el concepto de liberación. 
a los obispos de Brasil reunidos en Itaici que la TDL bien comprendida y arraigada en la tradición bíblica y eclesial, es no solo oportuna, sino útil y necesaria para América Latina.

La Conferencia de Puebla (1979) mantiene el método ver-juzgar-actuar de Medellín y defiende la opción preferencial por los pobres, pero ya no tiene el dinamismo profético de Medellín.

La Conferencia de Santo Domingo 1992, que se celebrará tres meses después del Encuentro de El Escorial 1992 para hacer memoria de los 500 años de la primera evangelización, cambiará la metodología latinoamericana y su lema es una nueva evangelización, la promoción humana y la cultura cristiana. Este cambio de metodología significa un cambio de rumbo, una vuelta a una postura más conservadora, un golpe de timón en la pastoral eclesial, aunque en Santo Domingo de hecho haya una significativa apertura hacia las culturas indígenas y africanas, y una cierta atención a la cultura moderna, llamada cultura adveniente ${ }^{9}$.

En este ambiente tiene lugar el Encuentro de El Escorial 1992, convocado de nuevo por el Instituto Fe y Secularidad de Madrid ${ }^{10}$.

Gustavo Gutiérrez no asiste por "insalvable coincidencia de fechas y otras dificultades", pero conserva los mejores recuerdos del Encuentro de El Escorial 1972, que dice que significó mucho para el desarrollo de la reflexión teológica de América Latina. Reconoce que en estos años la pobreza se ha acrecentado en el continente y que ha habido compañeros de ruta que han dado su vida hasta el extremo, y exhorta a mantener tercamente la esperanza y la alegría pascual, recordando con Bartolomé de las Casas que Dios tiene memoria viva y reciente de los pobres ${ }^{11}$.

Leonardo Boff, quien durante estos años ha sufrido duras advertencias, confrontaciones y críticas de parte de la Congregación para la Doctrina de la Fe, que le impuso un año de silencio, cumplido fielmente con sentido penitencial por Boff, también escribe una carta a los participantes del Encuentro comunicándoles que deja la Orden Franciscana y el ministerio, pero que seguirá luchando por la liberación de los pobres y el seguimiento de Jesús y su causa.

Se mantiene en el Encuentro la metodología de partir de la realidad latinoamericana, tanto social (M. A. Garretón, X. Gorostiaga) como eclesial (J. Comblin), se reflexiona sobre el Éxodo (C. Bravo), sobre las comunidades de

9. Cf. V. Codina, Diario de un teólogo del posconcilio, op. cit., pp. 200-211.

10. J. I. González Faus y J. Sobrino (eds.), Cambio social y pensamiento cristiano en América Latina, Trotta, Madrid, 1993.

11. Ibid., pp. 15-16. 
base (R. Muñoz) ${ }^{12}$ y sobre la dimensión popular de la teología (D. Irarrázaval), pero hay novedades significativas: la TDL se ha convertido ahora en una teología del martirio (J. Sobrino), hay una presencia de la teología femenina en América Latina (Ivonne Gebara), se presentan críticas y autocríticas a la TDL (J. L. Segundo) $)^{13}$, se abre el espacio para dialogar con otras teologías en clave liberadora de Europa (J. B. Metz), África (J. Lois) y Asia (G. Gispert Sauch), y se enfoca el tema del futuro de la TDL en América Latina (P. Trigo) y de la Iglesia latinoamericana (Mons. A. Celso Queiroz).

La ponencia que se me había pedido que versara sobre la fe latinoamericana frente al desencanto occidental comparó la lógica occidental de la razón instrumental (tanto de la primera como de la segunda Ilustración) con la razón simbólica más propia de América Latina, lo cual me valió la acusación de algunos españoles de ser excesivamente crítico con la modernidad ilustrada occidental y de querer volver a una cristiandad medieval y barroca, cosa que jamás pensé... En cambio, creo que los latinoamericanos participantes en el Encuentro la comprendieron perfectamente.

Quizás la ponencia de J. B. Libanio es la que mejor resume en forma de tesiseje el camino recorrido en estos 20 años ${ }^{14}$ :

- De una cristología del Jesús histórico en la perspectiva del seguimiento y de la identificación con el pobre, pasando por una Trinidad liberadora, hasta una pneumatología incipiente.

- De una salvación como liberación, pasando por mediaciones en la historia, a la creación de utopía en referencia al Reino, sobre todo en la lucha por la vida.

- De una eclesiología de experiencias comunitarias a una verdadera eclesiogénesis en una reinterpretación radical del poder y del ministerio en la Iglesia, en relación con el Reino y el mundo.

12. Este aporte del teólogo chileno Ronaldo Muñoz (fallecido en diciembre de 2009) fue, a mi parecer, uno de los más profundos, bellos y auténticos del Encuentro: en las comunidades de la base, frente a las necesidades básicas y de solidaridad del pueblo pobre, la Iglesia es una Iglesia samaritana; frente a la necesidad de afecto y fiesta, la Iglesia es un hogar; frente a la búsqueda de Dios y de sacramento, la Iglesia es santuario; frente al anhelo de sentido y de esperanza, la Iglesia es misionera; frente a los derechos negados y la lucha, la Iglesia es profética. Una síntesis tan vivencial no se improvisa, corresponde a un teólogo profundamente arraigado en el pueblo, evangélico y coherente, que unió de modo ejemplar cercanía a los pobres y seriedad teológica.

13. J. L. Segundo con ironía pidió permiso a la sala para citar un par de aportes del marxismo y, por otra parte, fue muy crítico frente a una teología basada en la "escuta do povo".

14. J. B. Libanio, Panorama de la teología de América Latina en estos últimos veinte años, pp. 57-78. 
- De una concepción transformadora de la acción del hombre a la creación de la nueva tierra y de los nuevos cielos con apertura a la ecología y al problema de la Tierra.

- De una teología preocupada por las estructuras sociales a una teología abierta a las culturas (etnias), en vista de una real inculturación e inserción en la doble dimensión de práctica y fiesta del pueblo latinoamericano.

Seguramente, estas tesis de Libanio señalan no solo lo que la TDL ha cambiado en estos veinte años, sino también perspectivas de futuro a las que se abre. Por su parte, J. I. González Faus resumió lo vivido teológicamente en el Encuentro como el paso de una alternativa inmediata a un fermento a largo plazo ${ }^{15}$.

Sintetizando la experiencia de este segundo Encuentro de El Escorial 1992 y comparándola con el Encuentro de 1972, yo diría que se ha pasado del entusiasmo profético y liberador del Éxodo a la dura situación del pueblo de Israel en el exilio: un tiempo de gracia, de conversión y de espiritualidad, de reafirmación de la fe y fortalecimiento del sentido comunitario, de apertura a culturas y religiones extranjeras. En el contexto del exilio y del postexilio surgen los cánticos del Siervo de Yahvé, la fe en el Dios creador del cielo y la tierra, los libros sapienciales, el protagonismo de las mujeres, la apertura a la dimensión erótica del amor, las primeras reflexiones sobre el sufrimiento, el mal y la muerte.

En este segundo Encuentro de El Escorial 1992 se ha constatado, como en el exilio de Israel, el sufrimiento y el martirio del pueblo y de los mismos teólogos, se ha vivido una purificación dolorosa y penitencial, una cierta debilidad y quizás nostalgia del pasado, pero también una mayor madurez sapiencial, una mayor espiritualidad y cierta apertura a otras realidades diversas, antes no intuidas o por lo menos no explicitadas: género y sexualidad, culturas y religiones, cosmos y tierra..., y todo ello en un clima de esperanza pascual, en medio de la noche oscura del invierno eclesial y del silencio de Dios ${ }^{16}$.

\section{Congreso Continental de Teología, Unisinos (São Leopoldo) 2012}

Este evento tuvo como telón de fondo los 50 años del Vaticano II y los 40 años de la TDL. Convocado y auspiciado por una serie de instituciones teológicas (Amerindia, Universidad Unisinos, Universidad Javeriana, Soter, Asociación Teológica de México...), se celebró en un clima diferente al del anterior Encuentro: bajo el pontificado de Benedicto XVI, después de la Asamblea de Aparecida (2007), con participación de 750 personas, entre jóvenes y adultos, laicas y laicos, religiosas y religiosos, sacerdotes, 23 obispos, y hermanas y

15. Ibid., p. 346.

16. Cf. V. Codina, Diario de un teólogo del posconcilio, op. cit., pp. 191-194. 
hermanos de otras confesiones, provenientes de diferentes países de América Latina y el Caribe, de América del Norte y de Europa.

En su preparación no faltaron presiones romanas a las universidades convocantes cuestionando y frenando su celebración; otros grupos de Iglesia criticaban la presencia de teólogos a los que consideraban sospechosos, como Boff, Sobrino, Frei Betto, y creían que el Congreso iba a constituir una fuerte crítica y ataque a la Iglesia jerárquica.

Nada de esto sucedió. El Congreso se desarrolló en un ambiente de serenidad y sentido eclesial, como un ejercicio de discernimiento de las diferentes hermenéuticas del Vaticano II y de los signos de los tiempos, con un carácter celebrativo y a la vez prospectivo, en un clima de oración y de comunión eclesial ${ }^{17}$.

Como afirma Agenor Brighenti, coordinador de Amerindia en la presentación del pretexto y contexto del Congreso ${ }^{18}$, este siguió los grandes ejes temáticos de la TDL: una teología como acto segundo (G. Gutiérrez), teología del cautiverio (L. Boff), una teología que ejercita el intellectus misericordiae (J. Sobrino), una TDL que sea liberadora de la teología (J. L. Segundo), una teología no cínica (H. Assmann), profética (J. Comblin), articulada desde una Iglesia de liberación (J. B. Libanio).

Dentro de la dimensión rememorativa del Congreso, hubo un recuerdo emocionado de los teólogos y teólogas ya fallecidos: J. L. Segundo, H. Assmann, J. Comblin, C. Bravo, S. Galilea, I. Ellacuría, X. Gorostiaga, R. Muñoz, Teresa Porcile, Carmelita Freitas, Antonio Parecida da Silva (Toninho), Antoniazzi, J. Jiménez Limón, M. de C. Azevedo...

Gustavo Gutiérrez no pudo asistir por motivos de salud, pero envió una comunicación desde la Universidad Notre Dame de Estados Unidos, en una videoconferencia en la que exhortó a los jóvenes teólogos a ser rigurosos, profundos, cercanos a las comunidades insertas en el mundo y que den su vida por los pobres. Invocó a todos los participantes a seguir la línea de lo mejor de la teología latinoamericana "cerca de Dios y cerca de los pobres", frase que puede resumir el sentido del Congreso y que se asumió en su mensaje final.

Participaron en las ponencias nuevas figuras de teólogas (Geraldine Céspedes, Marilú Rojas) y de teólogos (C. Mendoza), sin embargo, se criticó la poca presencia femenina en las ponencias y la ausencia de teólogos indígenas y africanos, por más que hubo una presencia femenina e indígena en los talleres y seminarios de la tarde.

17. Memorias del Congreso Continental de Teología, Unisinos, Brasil, 50 años del Vaticano II. Análisis y perspectivas, Paulinas, Bogotá, 2013. Además, se publicaron virtualmente otros dos libros sobre los talleres y comunicaciones del Congreso.

18. Ibid., pp. 12-19. 
No es fácil sintetizar lo más novedoso del Congreso, pero hay que citar la dimensión ecoliberadora y ecofeminista de la teología (L. Boff, Marilú Rojas), el diálogo con las culturas y los nuevos sujetos (L. C. Susin), un nuevo paradigma liberador que, manteniendo la opción por los pobres y el seguimiento del Jesús histórico, avance en temas como la sociedad moderna y postmoderna globalizada y del conocimiento, incida en la liturgia y religiosidad popular, propicie nuevas estructuras eclesiales, una mayor concreción jurídica del Vaticano II y de Medellín, un nuevo lenguaje teológico y una pastoral familiar en moldes plurales (J. B. Libanio).

Hubo una referencia a las teologías de la liberación de Asia (P. C. Phan) y a la teología moderna europea, muy anclada en la secularidad moderna y en este sentido un tanto alejada del mundo religioso y popular de América Latina (A. Torres Queiruga).

Mi ponencia sobre las Iglesias del continente 50 años después del Vaticano II y algunas cuestiones pendientes, glosó la recepción latinoamericana del Vaticano II que se dio sobre todo a partir de la Gaudium et spes y su teología de los signos de los tiempos en Medellín, y cuestionó algunos aspectos de la TDL clásica: ¿demasiado moralista y voluntarista?, ¿riesgo de milenarismo?, ¿muy paternalista y patriarcal?, ¿poca sensibilidad a temas como la gratuidad, la fiesta, la sexualidad, la salud? Y sobre todo insistió en la necesidad de la elaboración de una pneumatología desde abajo, desde los pobres, que ayudase a comprender desde dentro la irrupción de los pobres en la sociedad y en la Iglesia, el pluralismo de sujetos, la santidad primordial y el martirio, los nuevos signos de los tiempos, etc.

Indudablemente, el Congreso tuvo un cierto sentido no solo rememorativo, sino también un poco nostálgico (saudade) de los gloriosos años setenta y ochenta, y fue significativa la foto de los "dinosaurios" presentes en el Congreso de Unisinos ${ }^{19}$. No asistieron Clodovis Boff, E. Dussel, Ivonne Gebara, R. Oliveros, que forman parte de la historia de la TDL.

Esta breve reseña y apretada síntesis del Congreso de Unisinos no puede expresar la riqueza de ponencias y talleres, pero muestra ya las líneas de fuerza que se evidenciaron aquellos días. Como afirma el mensaje final, la TDL está viva y continúa inspirando las búsquedas y los compromisos de las nuevas generaciones, pero a veces es brasa que se esconde bajo cenizas. El Congreso ha sido

19. En ella aparecen en este orden: J. Marins, C. de Lora, P. Trigo, Elsa Támez (¡la única mujer!), J. Sobrino, P. Suess, L. Boff, J. B. Libanio, P. Richard, J. García, V. Codina, J. C. Scannone, Frei Betto, J. Hernández Pico, C. Mesters, J. O. Beozzo, Eleazar López, F. Chico Whitaker, D. Irarrázaval. Y en el trasfondo aparecen las figuras de G. Gutiérrez y de S. Torres que, por motivos de salud, no pudieron asistir al Congreso de Unisinos. Sin duda, es una foto para la posteridad... 
un soplo que ha reencendido la llama de esta teología que quiere ser fuego que encienda otros fuegos en la Iglesia y en la sociedad ${ }^{20}$.

La gran afluencia de jóvenes en Unisinos es una señal de esperanza de cara al futuro. Hay algo innegociable: el seguimiento del Jesús histórico de Nazaret y la opción por los pobres. Pero hay una pluralidad de sujetos y de temas nuevos: jóvenes, mujeres, indígenas y africanos, culturas, religiones, ecología, pneumatología... El aporte socio-analítico de los años setenta y ochenta es irrenunciable, pero se ha de completar con un análisis antropológico, de género, etario, de culturas y religiones, de ecología. No hay una TDL, sino muchas teologías liberadoras, esto es, hay diferencias dentro de un aire de familia común.

Si la TDL ha partido siempre de la realidad social y eclesial, un profundo cambio epocal como el que estamos viviendo no puede dejar de impactar e influenciarla. Hay una profunda crisis de los sistemas económicos y sociales hasta ahora vigentes, hay un descontento general que se expresa en la indignación de los jóvenes y el deseo de un mundo diferente. También a nivel religioso y espiritual nos hallamos ante un cambio del tiempo axial que ha estado en vigor durante siglos, quizás desde el Neolítico y que implica un profundo cambio en la estructuración de las religiones ${ }^{21}$. Estamos siendo sacudidos, a nivel mundial, por una especie de terremoto o tsunami de proporciones desconocidas hasta ahora.

América Latina también está viviendo profundos cambios tanto a nivel sociopolítico como eclesial. A nivel político, mencionemos todo el movimiento y proceso que se ha llamado "el socialismo del siglo XXI", la emergencia de nuevas potencias como Brasil, los fenómenos migratorios, el narcotráfico, las maras o pandillas juveniles, el aumento de la violencia y de la inseguridad ciudadana, el despertar de los pueblos indígenas y africanos, el descontento y desconcierto de los jóvenes, el impacto de las nuevas tecnologías, la fragilidad de la familia, la problemática de género y las nuevas formas de vivir la sexualidad, el cambio climático y la problemática ecológica, entre otros.

A nivel eclesial, aunque se mantiene un profundo sentido religioso en la gran mayoría del pueblo, existe un gran pluralismo de opciones religiosas y espirituales, desde la vuelta a las religiones ancestrales y un rechazo del cristianismo tildado de colonial, al agnosticismo y ateísmo, pasando por católicos de la religiosidad popular con creencia pero poco sentido de pertenencia eclesial, católicos conscientes y comprometidos, comunidades evangélicas y pentecostales, religiones asiáticas, etc. La Iglesia de cristiandad está en profunda agonía, aunque su desaparición sea muy lenta y desigual, según los países.

20. Ibid., p. 206.

21. Cf. K. Jaspers, The Original Goal of History, New Haven, 1953. 
América Latina, considerada como la reserva espiritual de la Iglesia católica, una especie de "Amazonía cristiana", el continente de la esperanza, está ahora en crisis y amenazada, como la misma Amazonía. Aparecida reconoce que no subsistirá al embate del tiempo moderno una fe reducida a moralismos, a conceptos y prácticas sacramentales inconexas ${ }^{22}$. De ahí la invitación urgente de Aparecida a pasar de meramente bautizados a discípulos y misioneros de Jesucristo. Todo este cambio de panorama ¿no es un desafío para la TDL del futuro?

\section{Epílogo}

Creo que los tres encuentros (El Escorial 1972, El Escorial 1992 y Unisinos 2012) señalan con suficiente claridad la trayectoria, vicisitudes, cambios y desafíos de la TDL.

Pero la vida sigue y la historia siempre aporta novedades y sorpresas. Desde la celebración del Congreso de Unisinos, en octubre de 2012, al presente, hemos vivido un inesperado cambio en la cúpula eclesial: la ejemplar renuncia de Benedicto XVI y la elección del nuevo obispo de Roma, Francisco.

Es difícil e imprevisible saber las consecuencias eclesiales de estos cambios, pero no podemos olvidar que la figura de Josef Ratzinger, primero como prefecto de la Congregación para la Doctrina de la Fe y luego como papa, ha jugado un papel muy importante en la recepción del Vaticano II y muy en concreto en la valoración romana de la TDL. Basta recordar sus afirmaciones muy críticas que desde el comienzo ha manifestado hacia la recepción rupturista que se ha dado del Vaticano II y la TDL, a la cual consideraba que estaba inficionada de marxismo y a la que, en el mejor de los casos, le concedía la categoría de moral, pero no la de ser una genuina teología al estilo de las europeas ${ }^{23}$. Con la renuncia de Ratzinger, se cierra una etapa postconciliar y parece que acaba el invierno eclesial.

Y esto porque el nuevo obispo de Roma, Francisco, abre perspectivas nuevas de cara a la Iglesia y a la misma teología latinoamericana. No vamos a repetir todo lo que ya se ha escrito sobre los nuevos gestos simbólicos y el nuevo lenguaje que ha empleado, signos de un nuevo clima eclesial que recuerda al inaugurado por Juan XXIII y a la subsiguiente, aunque breve, primavera postconciliar.

22. Aparecida 12. En realidad, el texto oficial aprobado por Roma dice "no resistiría", pero el texto aprobado por los obispos antes de la revisión romana era más realista: "no resistirá".

23. Véase el diálogo sobre este tema en la entrevista V. Messori y J. Ratzinger, Informe sobre la fe, Madrid, 1985. Cf. también V. Codina, Creo en el Espíritu Santo, Santander, 1994, pp. 145-148. 
La insistencia de Francisco en la Iglesia pobre y de los pobres está muy en convergencia con las intuiciones básicas de la TDL, aunque seguramente la dimensión liberadora de la teología de Bergoglio es más deudora de la teología argentina (Lucio Gera, Juan Carlos Scannone) que de otras formas de teología liberadora más ideológicas y dialécticas.

Esto explica no solo su sensibilidad hacia los pobres y hacia una Iglesia solidaria con ellos, sino su aprecio y respeto a la fe del pueblo, sencillo, a la religiosidad popular, a la sabiduría y cultura de los pobres. A esto se añade su apertura a las religiones de la humanidad, su perspectiva misionera, el deseo de una Iglesia que no sea autorreferencial y encerrada en sus muros, sino una Iglesia que salga a la calle, vaya a las fronteras, a las periferias existenciales, aun con el riesgo de posibles accidentes.

Este mismo sentido popular le lleva a compadecerse del sufrimiento del pueblo y a interpelar a la conciencia anestesiada de la sociedad del bienestar que vive como encerrada en una burbuja de jabón, incapaz de responder al clamor de los que sufren y de llorar por las víctimas de la insolidaridad de los poderosos.

Esto se ha puesto de relieve en la homilía pronunciada por Francisco en su primer viaje fuera de Roma, el 8 de julio de 2013, a la isla de Lampedusa, lugar adonde acuden gran cantidad de inmigrantes africanos indocumentados, muchos de los cuales en lugar de llegar a su soñado destino europeo, mueren en el mar en sus frágiles pateras o embarcaciones. Esta homilía, en el contexto de una celebración penitencial, significa todo un programa de gobierno eclesial, que se ha comparado con el discurso inaugural del Vaticano II, Gaudet mater Ecclesia, de Juan XXIII.

Efectivamente, en Lampedusa, Francisco no presenta una Iglesia fuerte que se impone a la humanidad (como en Juan Pablo II), ni tampoco simplemente una pequeña minoría testimonial en medio de la diáspora secular (como en Benedicto XVI), sino una Iglesia cuya fuerza le viene de la misteriosa presencia de Cristo en los pobres, en la línea de Mateo 25, una presencia que interpela en primer lugar a la Iglesia, pero también a la humanidad ${ }^{24}$. Los pobres son un lugar teológico privilegiado para la Iglesia y el mundo.

También el aplaudido mensaje de Francisco ante la multitudinaria presencia de jóvenes en la Jornada Mundial de la Juventud en Río de Janeiro ha confirmado esta línea teológica y pastoral: una Iglesia pobre y de los pobres, salir a las periferias, luchar por un mundo justo y solidario sin exclusiones, escuchar a los jóvenes que sueñan un mundo diferente y alternativo, etc.

24. Véanse las afirmaciones del historiador de la Iglesia de la escuela de Bolonia Alberto Melloni en una entrevista con Vatican Insider que publica La Stampa del 18 de julio de 2013, en http://vaticaninsider. la stampa. it/es/vaticano/dettagliospain/articolo/fra... 
Su última exhortación apostólica sobre el anuncio del Evangelio (Evangelii gaudium), en la que recoge los aportes del Sínodo de Obispos de octubre de 2012 sobre la nueva evangelización para la transmisión de la fe cristiana hoy, refleja el pensamiento y la hoja de ruta del nuevo obispo de Roma.

Desde el comienzo de este documento y a lo largo de todo él, aflora un sentimiento vivo de la alegría del Evangelio que llena el corazón y la vida entera de los que se encuentran con Jesús, en contraste con el riesgo de tristeza individualista, búsqueda de placeres superficiales y el aislamiento del mundo actual. Esta alegría es la que impulsa a los cristianos a evangelizar, a anunciar la buena y siempre nueva noticia de la salvación y del amor de Cristo. Por esto, los cristianos no deben tener cara de funeral ni de Cuaresma sin Pascua, sino irradiar al mundo la alegría de Cristo.

Esta alegría no es ingenua, pues reconoce los graves desafíos de hoy: una economía que mata y que exige del cristiano una postura de denuncia profética: no a la economía de exclusión, no a la nueva idolatría del dinero, no a un dinero que gobierna en lugar de servir. Eso implica positivamente acentuar la dimensión social de la evangelización y el compromiso de la Iglesia con los pobres y los excluidos de la sociedad, de modo que sea una Iglesia pobre y de los pobres, que escuche su clamor y trabaje por su inclusión social.

Todo esto supone un gran cambio y conversión en la Iglesia, una impostergable renovación eclesial de la parroquia, de las diócesis y del mismo papado, una Iglesia en estado de misión, que no se aferre a cosas que ya no tienen sentido hoy, que supere el pesimismo estéril, la mundanidad espiritual y las guerras y divisiones internas, que abandone el clericalismo que no es cristiano, y en cambio revalorice a los laicos y a la mujer, en unas relaciones nuevas entre todos los cristianos, nacidas del Señor.

Más allá de estas afirmaciones, la exhortación está corroborando y dibujando el nuevo estilo y modelo de Iglesia que promueve Francisco: de una Iglesia poderosa, distante, fría, acartonada, miedosa, reaccionaria, de la cual la gente se aleja y se va, a una Iglesia pobre, sencilla, cercana, acogedora, sincera, realista, que promueve la cultura del encuentro; de una Iglesia moralista obsesionada por el aborto, el control de la natalidad y el matrimonio homosexual, a una Iglesia que va a lo esencial, recupera el Evangelio, anuncia la gran buena noticia de la salvación en Cristo; de una Iglesia centrada en el pecado y que ha hecho una tortura del sacramento de la confesión y una aduana de la petición de sacramentos, a una Iglesia de la misericordia de Dios, de la ternura, de la compasión, con entrañas maternales, que refleje la misericordia del Padre; de una Iglesia centrada en ella misma, autorreferencial, preocupada por el proselitismo, a una Iglesia de los pobres, preocupada ante todo del dolor y del sufrimiento humano, de la guerra, del hambre, del paro juvenil, de los ancianos; de una Iglesia encerrada en sí misma, reliquia del pasado, con tendencia a mirarse el ombligo, con sabor 
a invernadero, que espera que vengan los otros, a una Iglesia que sale a la calle, callejea la fe, va a los márgenes sociales y existenciales, a las fronteras; de una Iglesia que discrimina a los que piensan diferente, a los diversos, a una Iglesia que respeta a los que siguen su propia conciencia; de una Iglesia con tendencia restauracionista y de vuelta atrás, que añora el pasado, a una Iglesia que considera que el Vaticano II es irreversible; de una Iglesia con pastores encerrados en sus parroquias, clérigos de despacho, que buscan hacer carrera, que acaban siendo coleccionistas de antigüedades, obispos siempre en aeropuertos, a pastores que huelan a oveja, que caminen delante, detrás y en medio del pueblo; de una Iglesia ONG piadosa, clerical, machista, monolítica, narcisista, a una Iglesia Casa y Pueblo de Dios, hogar, que respete la diversidad, donde jueguen un papel relevante los laicos, las mujeres, las familias; de una Iglesia envejecida, triste, con gente con cara de cadáver o sonrisas de azafata, a una Iglesia joven y alegre, levadura y fermento en la sociedad, con la alegría y la libertad del Espíritu, donde los jóvenes sean protagonistas.

Lo importante no es la TDL, sino una Iglesia liberadora y la liberación del pueblo. La TDL ha cumplido una función profética y ahora, con esta nueva primavera eclesial, se abren para la Iglesia y para la teología nuevos horizontes.

Corresponderá a la nueva generación de teólogas y teólogos — sobre todo, jóvenes, laicos, indígenas y africanos- no repetir lo ya dicho, sino abrirse a la novedad del futuro, confiando en la fuerza del Espíritu de Jesús que siempre está presente en la historia, aunque muchas veces, como el viento, no sepamos ni de dónde viene ni adónde va (Jn 3, 8). 